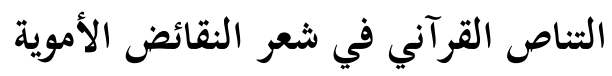

\title{
The Quranic Intertextuality in the Poetry of Opposites Umayyad
}

\author{
AHMED R. A. RAWAJBEH, TENGKU GHANI TENGKU JUSOH, MD. NOR ABDULLAH \\ \& ZULKARNAIN MOHAMED ${ }^{1}$
}

\begin{abstract}
The poets of opposites poems take their knowledge from multi-springs of knowledge. So, the direction of Islamic values were added to the knowledge that take from the past and its literature, and from present Islam and its acquaintances, so the poetic culture was colored with the color of the culture which they take. It was the way for the best poets to serve their purpose and to deliver their messages. There is no doubt that the Quran was afar distance of both recipient and poet for his eloquence this type of poem has been associated with the name of obscenity because of the large number insults and exposure of the taboos. This article came to reveal the relationship between the poetic text and the Quranic text in the poem of the three Umayyad poets and to wipe the dust of obscenity which knighted him and to identify the impact of the holy Quran upon its simple, compound and inspiration system and address the extent of correlation of poetic text and overlap with the Holy Quran.
\end{abstract}

Keywords: the Islamic trend, poets, the complexity of Quran, opposites, intertextuality.

$$
\begin{aligned}
& \text { التناص يعني تداخل النصوص،أي توظيف الشاعر لمقتبسات من نصوص في نصه الشعري، ويهدف الشاعر إلى توصيل } \\
& \text { رسائل معينة، ليؤدي التناص وظيفة مهمة، وهي توسيع أفضية المعنى في النص الشعري وتعميق التأثير في الملتقي. والتناص }
\end{aligned}
$$

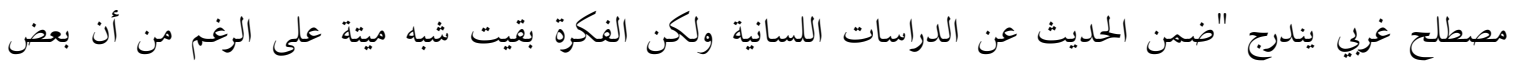

$$
\begin{aligned}
& \text { الشكلانين الروس من [شكلوفسكي] الذي فتق الفكرة، فاتخذها عنه [باختين] ، وقد حولها الأخير نظرية تعتمد على بنى } \\
& \text { التداخل بين النصوص" (al-Kalamy 2008) وقد بقي النص في الظل لا يرى نور الشمس حتى جاءت جوليا كرستيفا، }
\end{aligned}
$$

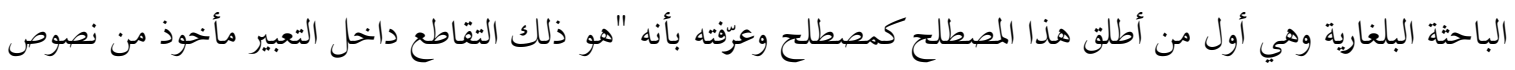

$$
\begin{aligned}
& \text { أخرى" ( Muhammad } 1995 \text { ( }
\end{aligned}
$$

\footnotetext{
${ }^{1}$ Ahmed A.R. Rawajbeh*(Corresponding author), M.A. Ministry of Education, Palestine; Tengku Ghani Tengku Jusoh, Ph.D. Professor at Dept. of Arabic Studies and Islamic Civilization, Universiti Kebangsaan Malaysia, 43600 Bangi Selangor, Malaysia, Email: tgtj@ukm.my; Md. Nor Abdullah. M.A \& Zulkarnain Mohamed, Ph.D. Lecturers at Dept. of Arabic Studies and Islamic Civilization, Universiti Kebangsaan Malaysia, 43600 Bangi Selangor, Malaysia. Email: naim@ukm.my.
} 
التناص القرآني في شعر النقائض الأموية

ويراه ناصر شبانه أنه "صيغة صرفية على وزن تفاعل مما تحمله هذه الصيغة الاشتقاقية من معاني المشاركة والتداخل، بما يعني تداخل نص في آخر سابق عليه، ليمسي لدينا نصان: نص سابق ونص لاحق، بينهما علاقة خاصة قد في

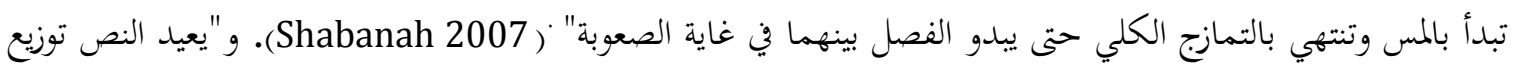
اللغة وهو حقل إعادة التوزيع هذه. إن تبادل النصوص، أشلاء نصوص دارت أو تدور في فلك نص يعتبر مركزا، وفي النهاية تتحد معه، هو واحد من سبل ذلك التفكيك والإنبناء: كل نص هو تناص، والنصوص الأخرى تتراءى فيه بمستويات

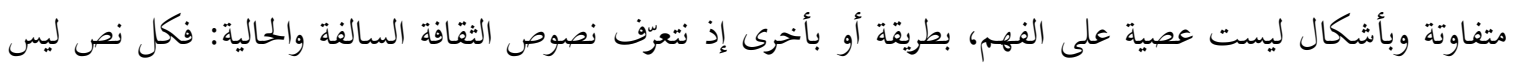
إلا نسيجا جديدا من استشهادات سابقة"(al-Biqa'iy 1998).

وعلى ضوء التعريفات السابقة نستطيع القول: إن كينونة التناص تتمثل في تداخل أو تشابك أو تعالق نص

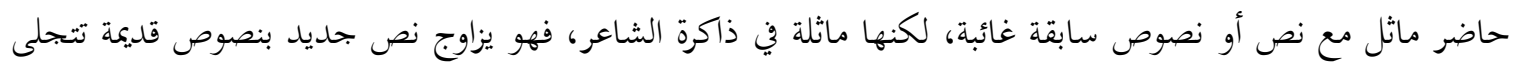
فيها ثقافة الشاعر ودرايته بالنصوص السابقة، ولعله من المقرر المعروف أنّ ثقافة أي إنسان هي حصيلة التعاطي مع ثقافات ئنات

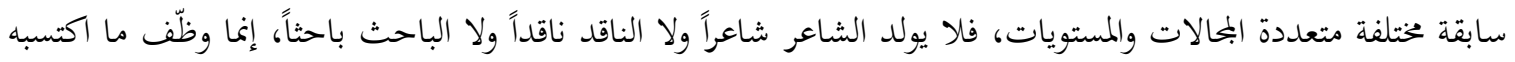

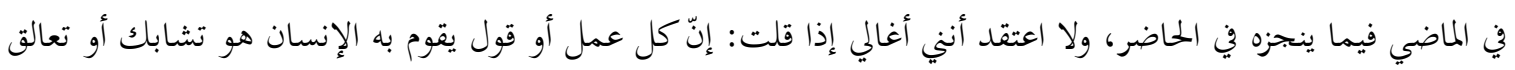
مع عمل أو قول سابق.

والتناص أكثر التصاقاً بين النص الماثل والنصوص الغائبة من الاقتباس، فهو ينحاز عنه بذلك، إذ إنّ الاقتباس

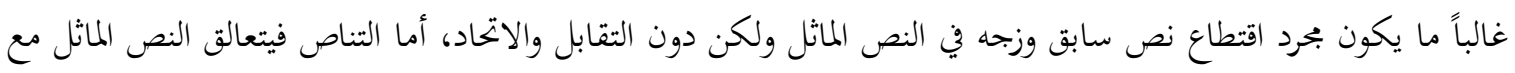
النصوص الغائبة إلى درجة الانصهار فلا يسهل الفصل بينهما، ذلك أنّه "يعتمد على تحويل النصوص السابقة وتمثيلها في نص مركزي يجمع بين الحاضر والغائب في نسيج مفتوح، قادر على الإفضاء بأسراره النصية لكل قراءة فعالة تدخله في شبكة اعم من النصوص" (al-Sa'dany 1991 (al).

\section{مظاهر التناص القرآني}

ولعل أهىى بتحليات الخطاب الديني تتمثل في القرآن الكريم كونه السمة القارّة في ذلك الخطاب، فانكفاء الشاعر اليه شعرياً تعني إعطاء مصداقية متميزة المعاني للخطاب الشعري انطلاقاً من مصداقية الخطاب القرآي نفسه، إذ إنّ القرآن الكريم يعد قمّة البيان العربي، وهو أسمي نموذج يحتذى أسلوبا وفكراً وهداية ودستور حياة. ولم يأت التناص القرآي في شعر النقائض مصادفة أو عفو الخناطر، بل كان مستحضراً يوظّف في سياقات المنجز الشعري تعميقا وإثراء فنيا وفكريا، ويبدو أن للثقافة الدينية التي تملكت الشعراء وقرب عهدهم بالنبوة وكثرة الفرق الدينية

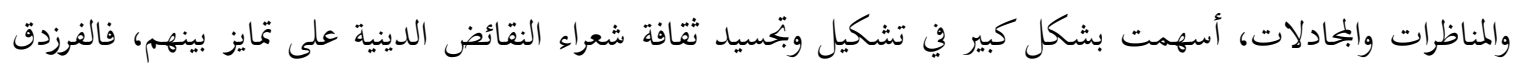

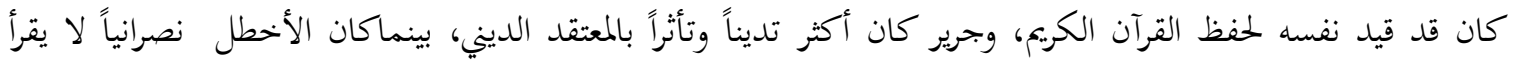

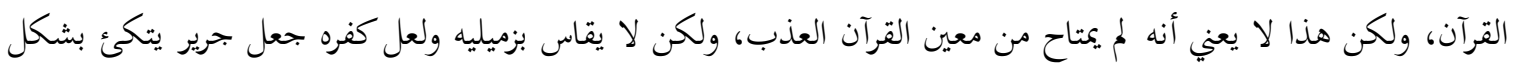
صائت على العنصر الديني ويجلد الأخطل به كلما أتيحت له الفرصة لذلك. 
فليس غريباً إذاً أن يُكسب القرآنُ الكريم شعرَ الفحول الأمويين رونقاً وجمالاً فنياً عن طريق التناص القرآني وتعالق

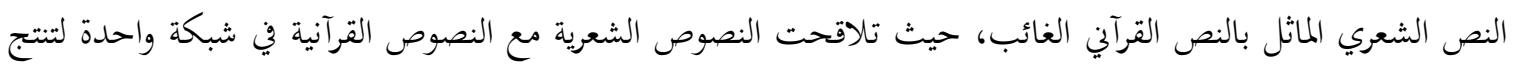

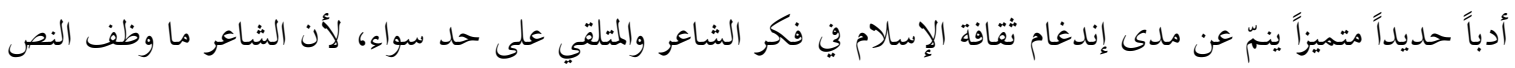

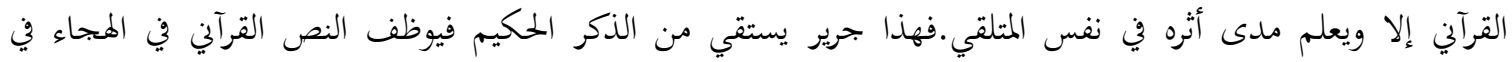

قوله (al-Basry 2007):

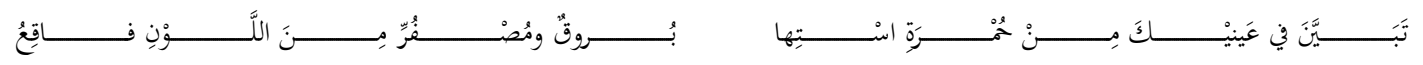

ولعل الشاعر يحيلنا في الشطر الثاني من هذا البيت إلى قوله تعالى في سورة البقرة، في بقرة بني إسرائيل: قَالُواً ادُُْ لَنَا رَبَّكًَ

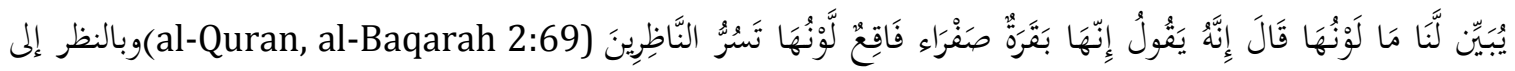

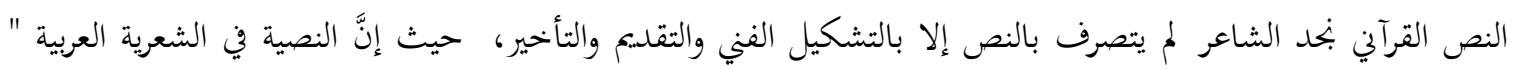

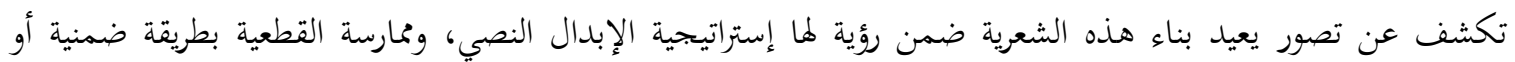
علنية"(Ibn Khalifah 2006) فهذا جرير يمارس هذه القطعية فيصنع نص متقاطع مع النص القرآي في هجاء الفرزدق

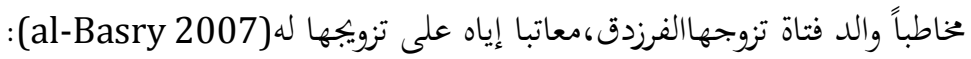

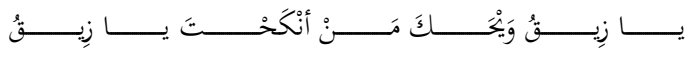

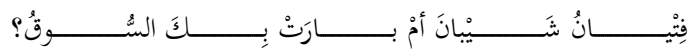

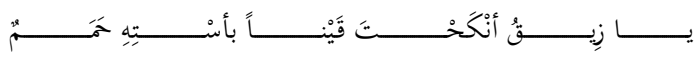

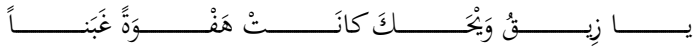

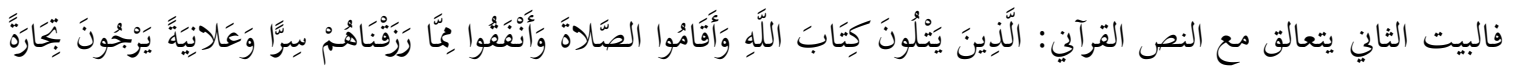

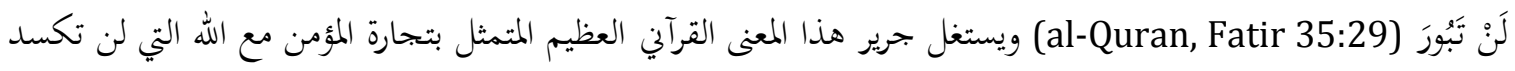

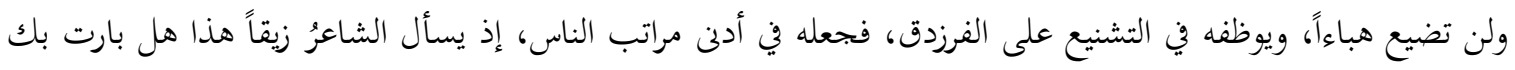

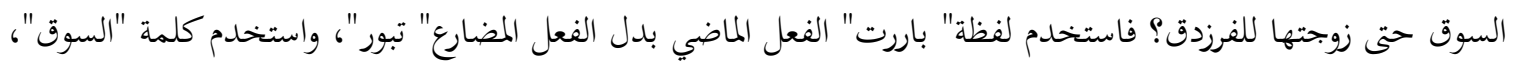

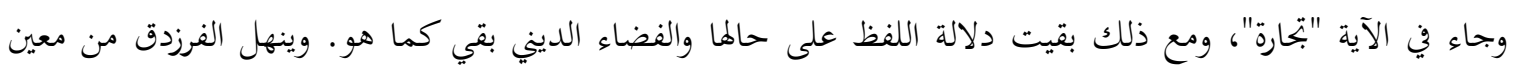

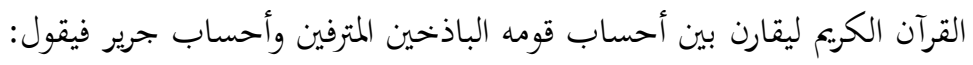

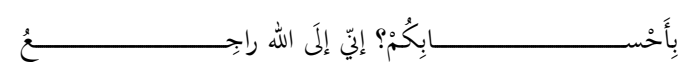

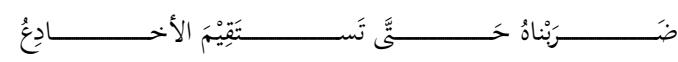

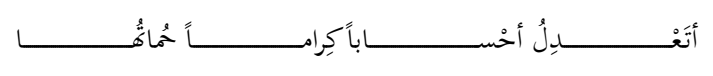

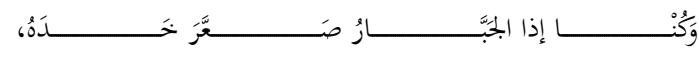

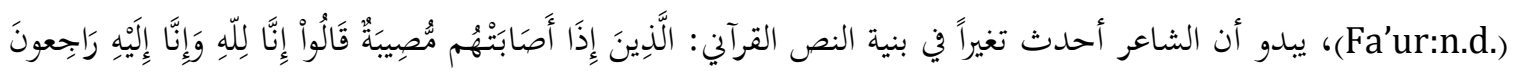

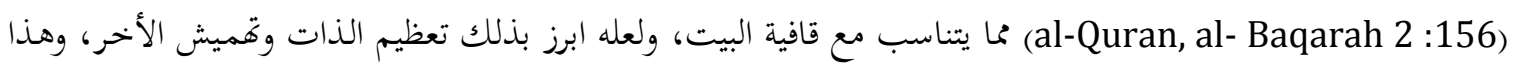

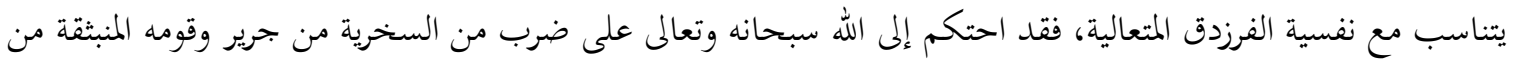


التناص القرآني في شعر النقائض الأموية

Rawajbeh, Tg. Ghani Tg. Jusoh, Md. Nor Abdullah \& Zulkarnain Mohamed

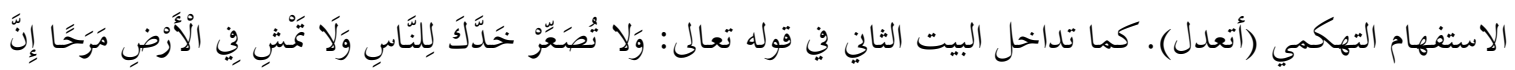

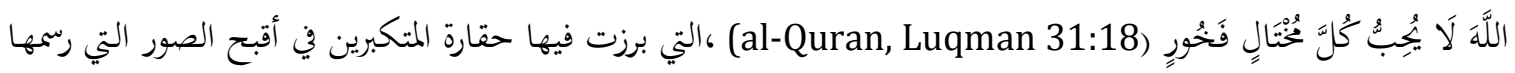

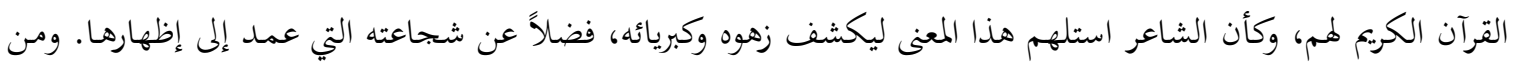

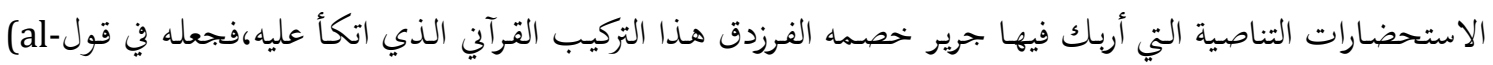

:Basry 2007)

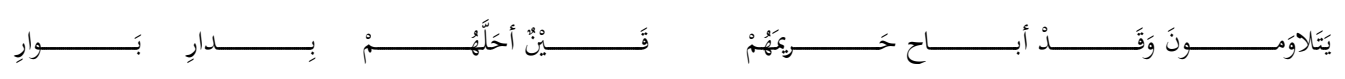

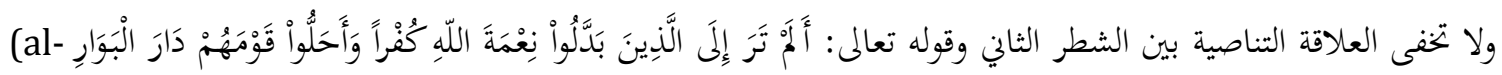
(Quran, Ibrahim 14:28،وهو يريد بذلك الهلاك، فجعل الصورة ترتسم ذاها كما رسمها القران الكريم بفارق الأفراد في

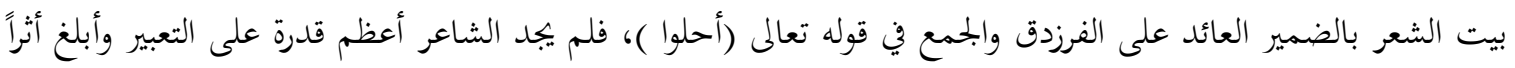
في النفوس من كلام الله تعلى فاستعاره لذلك، فيكون بذلك اعتمد على" تداخل النصوص أو تعالقها، تكثيفها أو تحاورها في بناء رسوبي عميق هو المقترب التناصي الذي بموجبه تفسر النصوص بعضها بعضا"(ald-Sa`dany 1999).

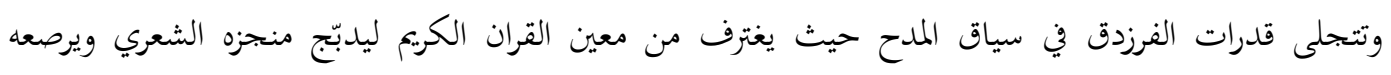

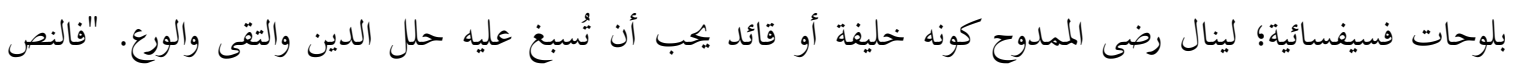

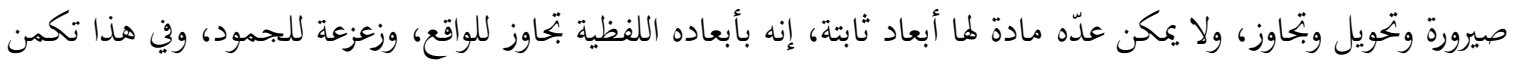

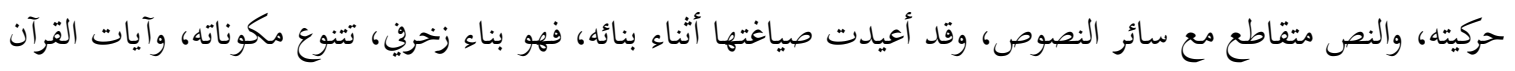

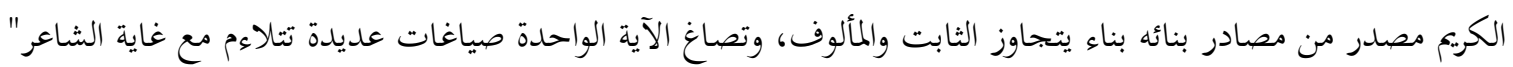
(Abu Sharar 2007)ففي مدحه لهشام بن عبد الملك أعاد صياغة النص القرآني، وجعله ينصهر في المنجز

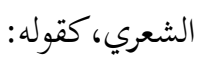

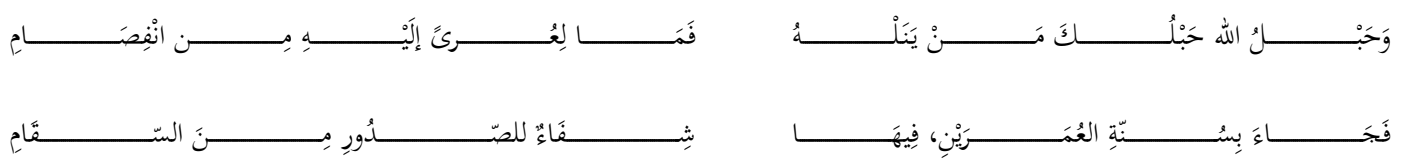

(Fa’ur: n.d)

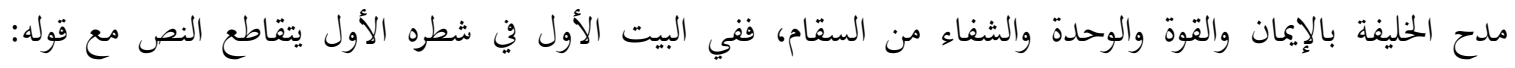

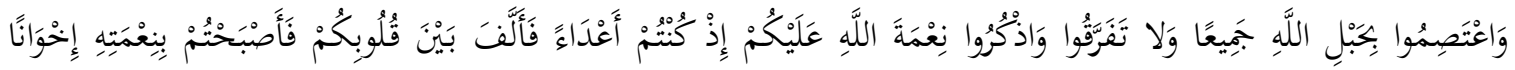

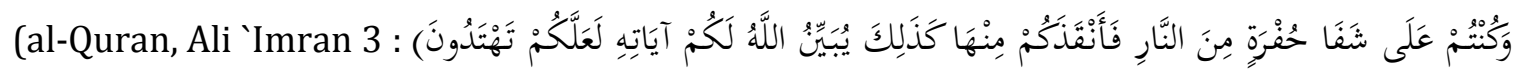

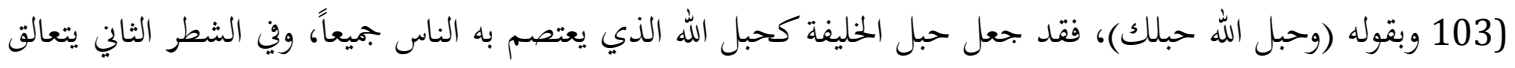

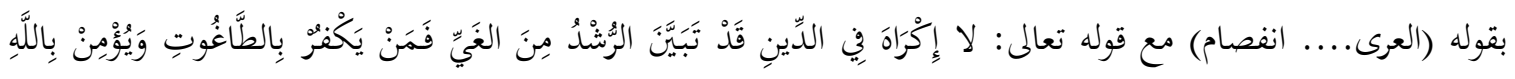

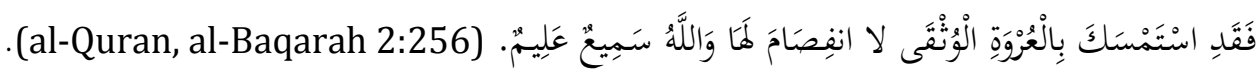


مع تغيير في بنية العرى التي جاءت "العروة" في الآية الكريمة ولكن الدلالة التي أرادها الشاعر تنسجم مع دلالة الآية الكريمة، فلا انفصام لمن يستمسك بالعروة الوثقى ويؤمن بالله، كما لا انفصام لمن يتمسك بحبل الخليفة ولا ينفصم عنه. وفي البيت

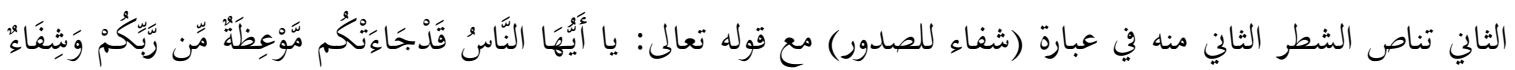

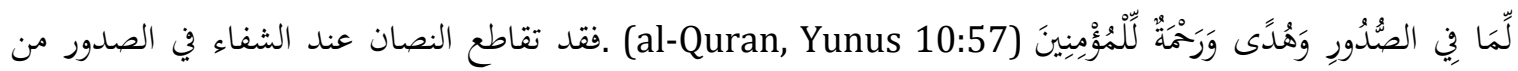
العلل والمرض، فالموعظة فيها شفاء ورحمة لصدور المؤمنين، وسنة العمرين التي التزمها هشام بن عبد الملك فيها شفاء لصدور المؤمنين من السقام والجهل والارتياب.

وبند الفرزدق يخاطب رفيق رحلته الذي انذ النعاس يداعب جفنيه، فيخلق فضاءات دينية تمتزج في بنية المنجز الشعري من خلال هذه الإشارات التي ينجح الشاعر في نقل المتلقي إلى حيث يريد ويجعله يعتقد بما يقوله مستفيداً من القوة

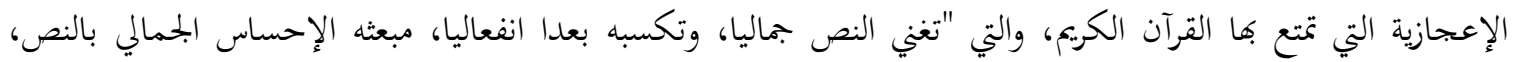

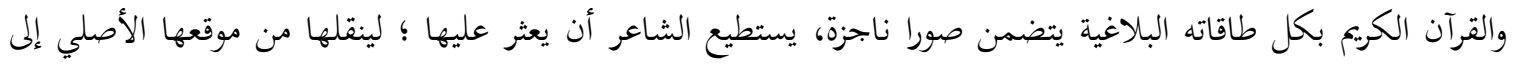
موقع جديد، يتناسب مع دلالتها؛ فتصبح جزءا من النص الشعري، تنسجم معه، وتتآلف مع عناصره؛ فتضحي عنصرا حيويا فعّالا، يتميز بقوة تأثيره ؛ فيتفوق في ذلك على باقي عناصر النص" (Fàur n.d) (Abu Sharar 2007)، كقوله : (Fa) :

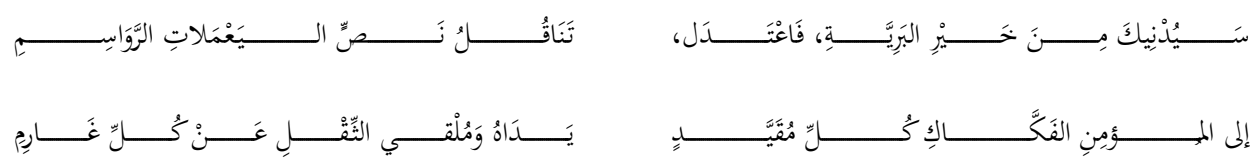

فمن الواضح أن الشاعر في البيت الأول فتح للمتلقي فضاءً روحانياً عندما وظف (خير البرية)التي ورد ذكرها في القرآن

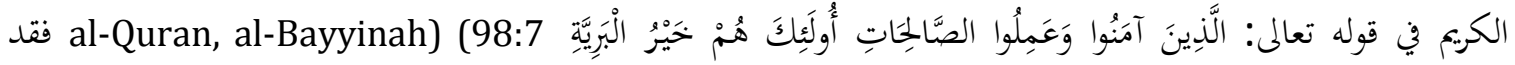

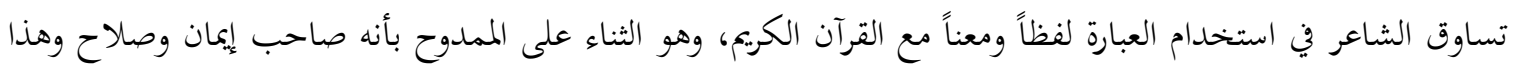
ما عبرت عنه الآية، ولعل ذلك يجعل المتلقي يثق بصدقية النص ويجعل الممدوح يشعر بالرضا والاطمئنان.

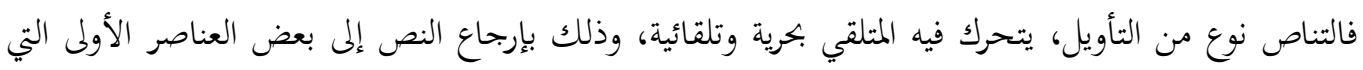

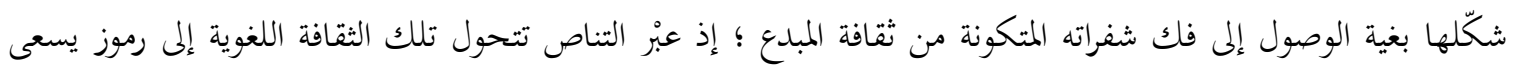
المتلقي لتفسيرها من أجل الوصول إلى ماهية الشعر، (Abu Sharar: 2007)، فهو حين يجعل من تكذيب الأخطل وقومه

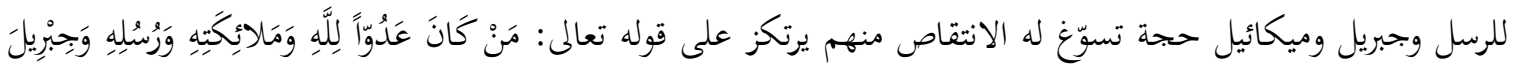

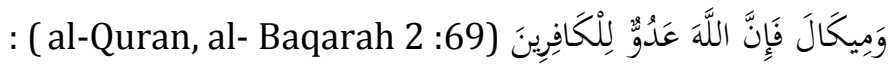

قَتَنِْي

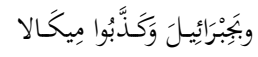

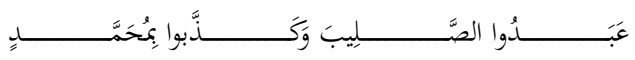

وفي معرض ترجيح كفة قيس على غيرها يقول (Tammas 2000):

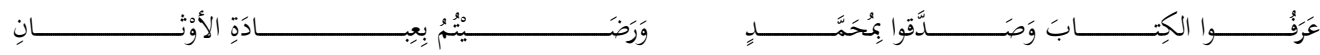


(al-Yasu`iy 1922) فقيس عرفت الحق وآمنت به واتبعته، على نقيض تغلب النصرانية، وكأنه بقوله (عرفوا الكتاب)

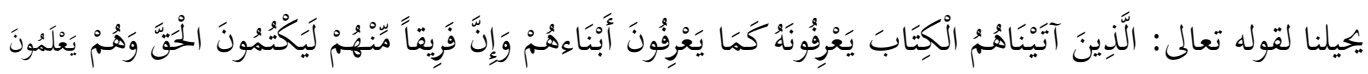

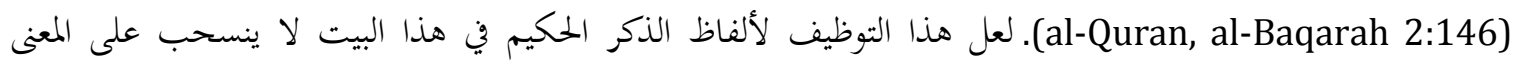

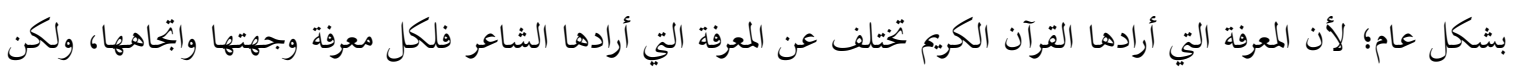

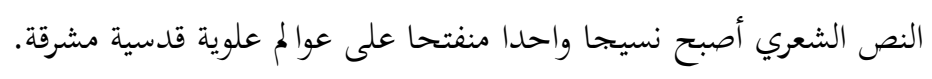

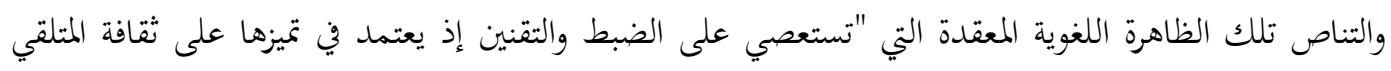

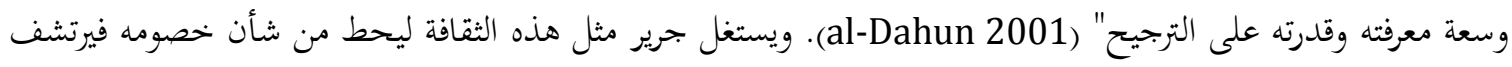

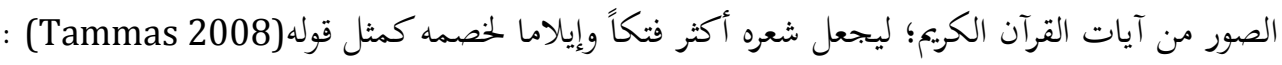

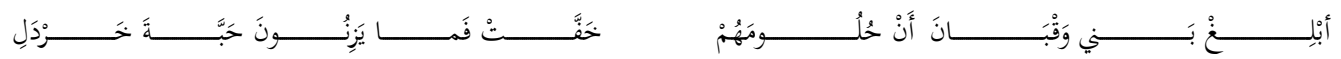

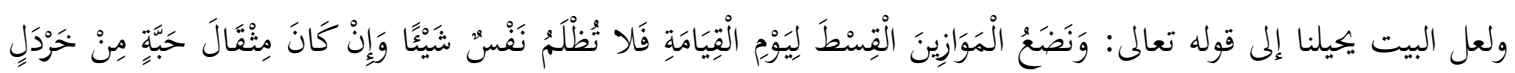

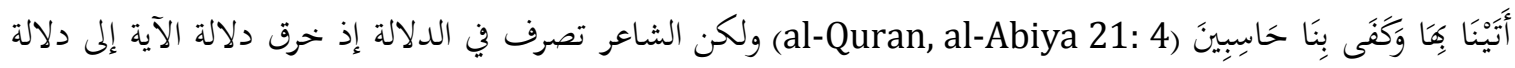

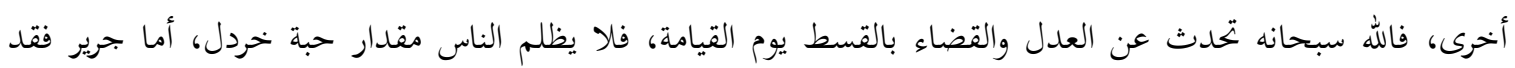

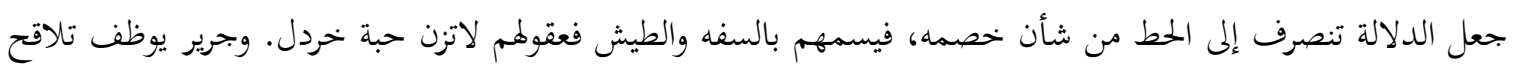

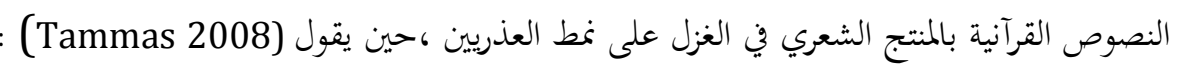
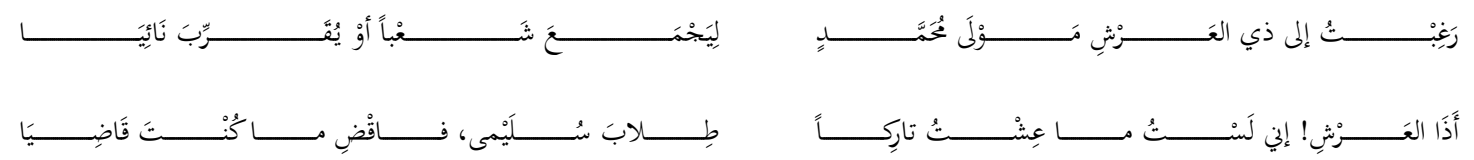

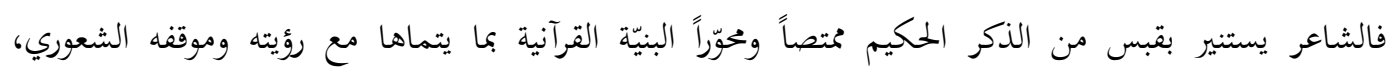

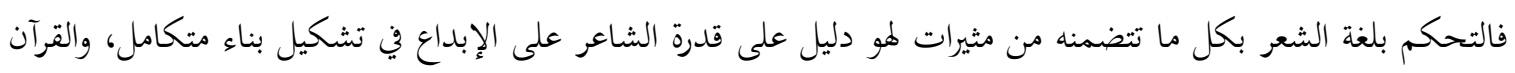

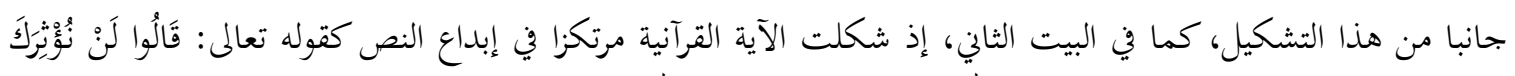

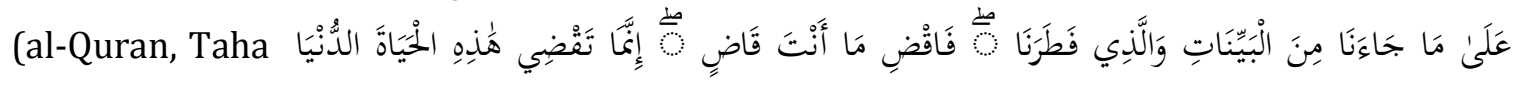

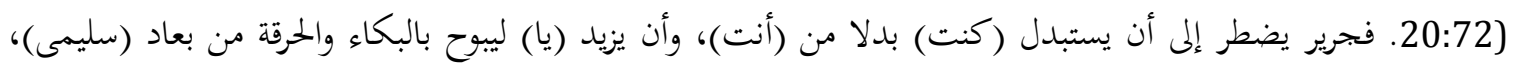

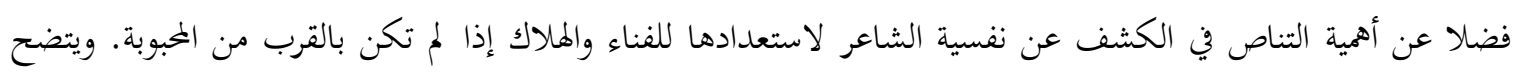

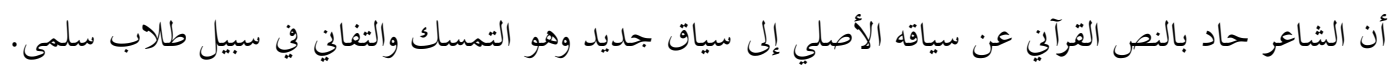

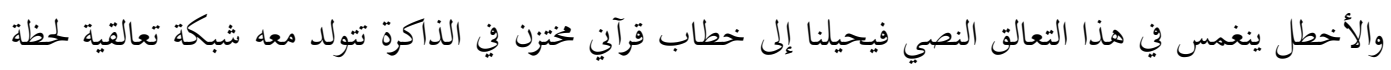

توليد النص الشعري فيلون منجزه بلوحة فسيفسائية مبدعة كقوله (al-Hawy:n.d):

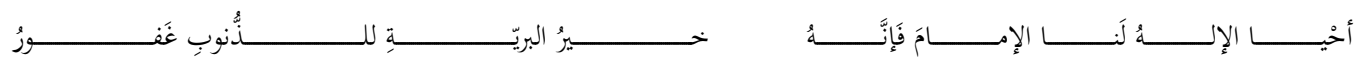




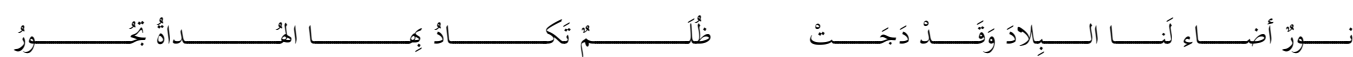

أفبما أنّ "القرائن المعرفية عادة تعمل على توسيع الأفق الدلالي للاستراتيجيات النصية الفاعلة في العمل الشعري" فقد جعل الممدوح يصطبغ بصبغة إسلامية خالصة ممطتيا هذه القرائن، حيث ارتكز على تناص (al-Sa’dany 1991)

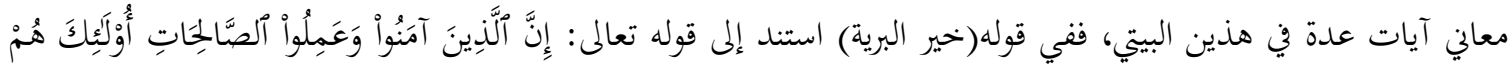

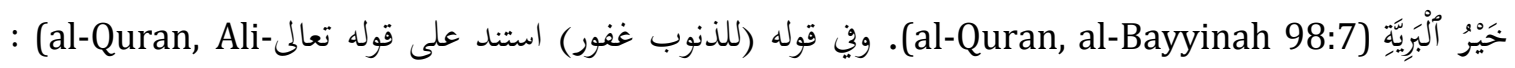

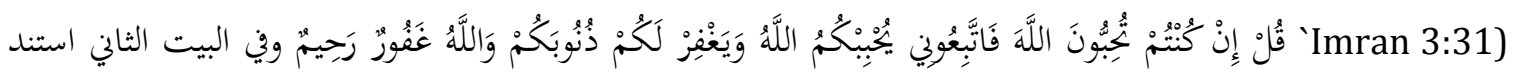

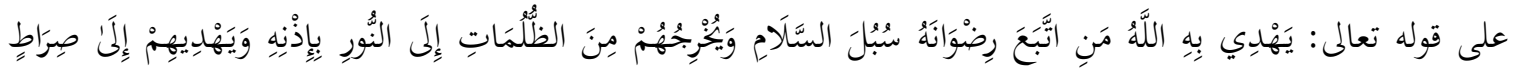

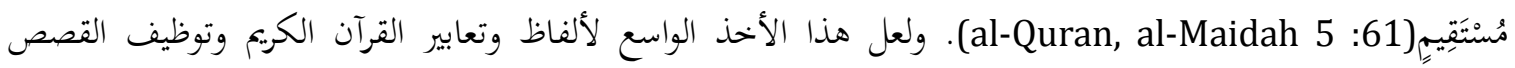
القرآي والمصطلحات الإسلامية، يشير بشكل أو بأخر إلى مدى واندغام الإسلام في ثقافة الشاعر وقدرته على التساوق معه كدين الدولة والمجتمع وإن كان لا يدين به، ومن ذلك قوله (al-Yasu iy 1922):

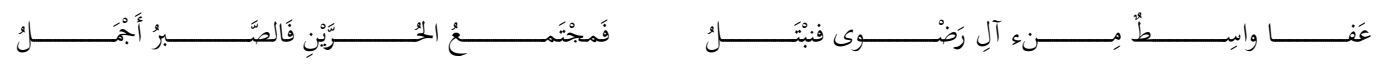

فنجد هنا أنه قد تحقق للأخطل في هذا البيت ما أراد، حيث استطاع بعبارة واحدة "أن يحيل إلى مشهد قرآني متكامل، ولكن في ذهنيته قارئ يشاركه ثقافته وبتربته" (Abu Sharar 2007) فعبارة (فالصبر أجمل ) ارتشفها الشاعر من آية كريمة فئم

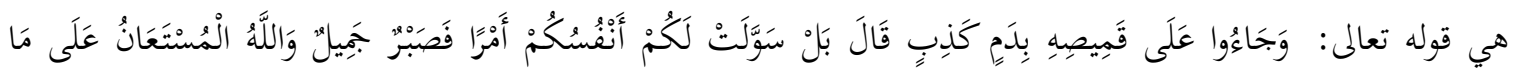

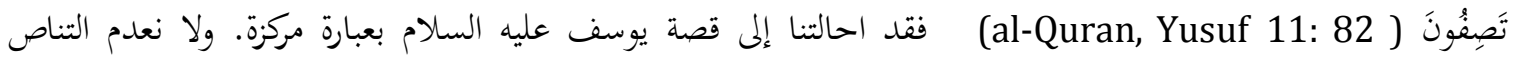
الإيحائي في الغزل فقد اتكأ عليه جرير في حديثه عن سماع صوت المحبوبة التي توهم قربها في قوله (Tammas 2008):

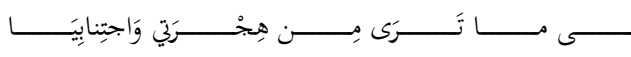

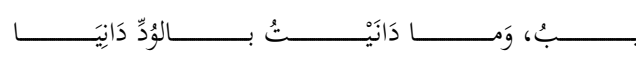

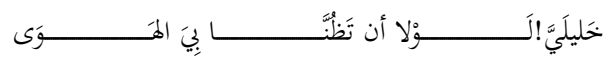

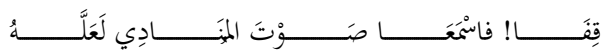

إنّه التنبؤ لسماع صوت المحبوب الذي يتوهم قربها، فيومئ للمتلقي بفتح فضاء القصص القرآين الذي تماثل فيه

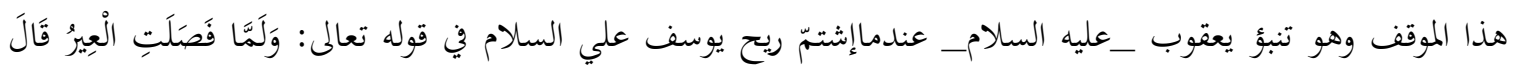

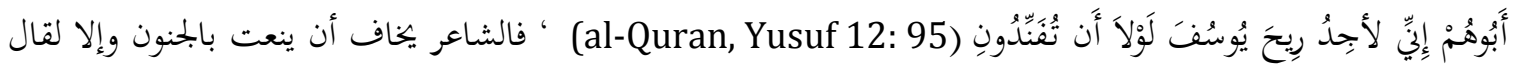
لصحبه: إنه يسمع صوت (عقيلة) تناديه. وهذا يرتد بنا إلى يعقوب عندما اشتم ريح ريح ابنه يوسف _عليهما السلامــ. على أن الاختلاف بائن في صدقية التنبؤ، فبشارة يعقوب _عليه السلام _على وجه الحقيقة لا التوهم، أما بشارة جرير بسماع صوت المحبوبة فهو وهم لا حقيقة. ومثل هذا التناص بنحه في قول الفرزدق كذلك (al-Yasu iiy 1922) :

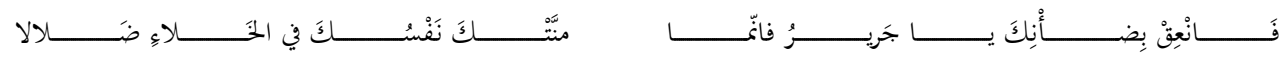


فهو يومئ هنا إلى آية قرآنية كريمة لم يذكرها في البيت وهي قوله تعالى (al-Quran, al-Baqarah 2: 14 وَإِذًا

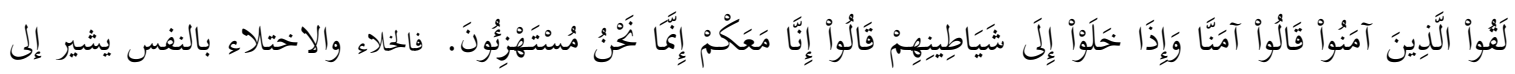

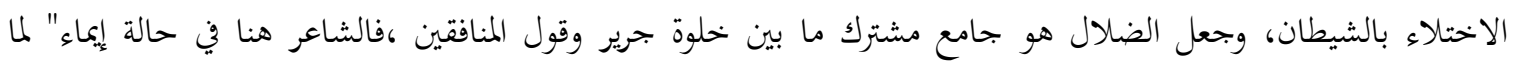

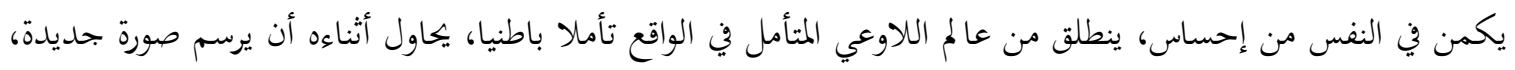
يشكلها الحدس لعالم غير خاص تشكيلا خاصا، تختفي معه هيئة ذلك العالم الراسخة في الذهن" (Abu Sharar 2007)

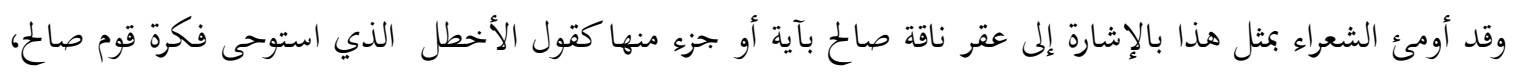

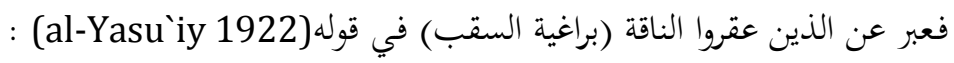

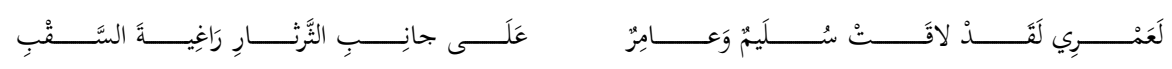

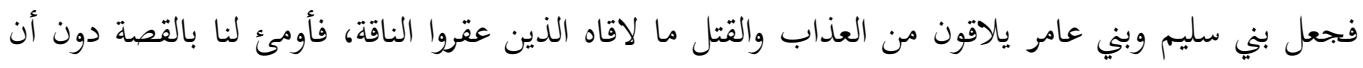

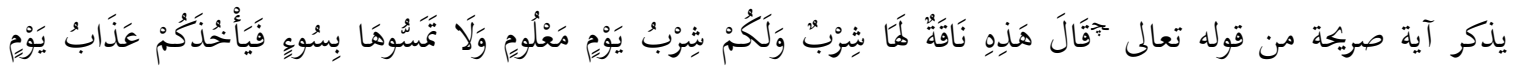

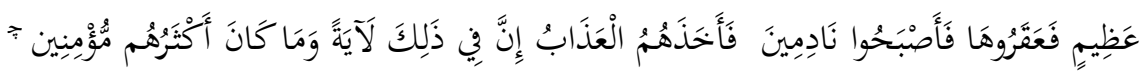

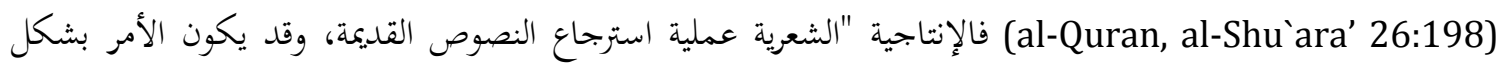

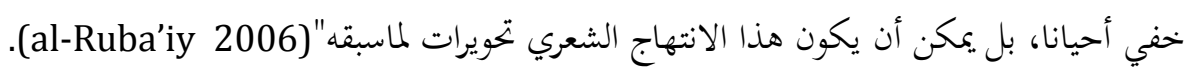

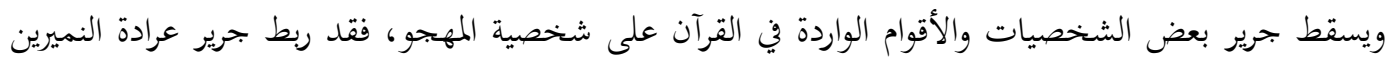

بقصة قوم لوط في قصيدته الدافقة وذلك يقول (Tammas 2008):
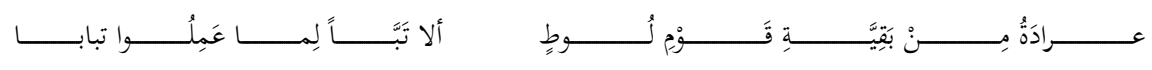

فقول الشاعر (قوم لوط ) يوحي للمتلقي وييله إلى قصة قوم لوط التي اختزها في الذاكرة ولارتباطها بالقرآن الكريم الذي

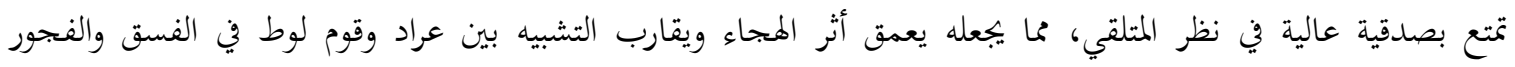

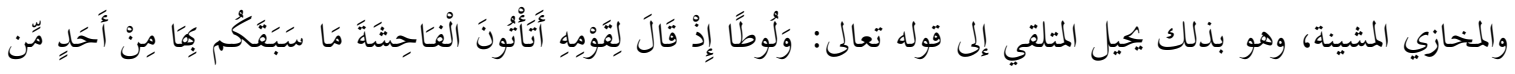

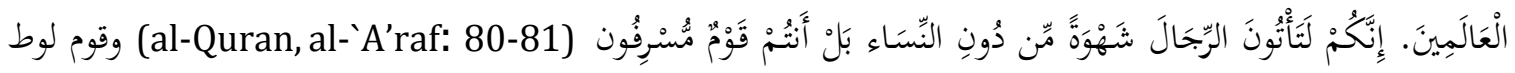

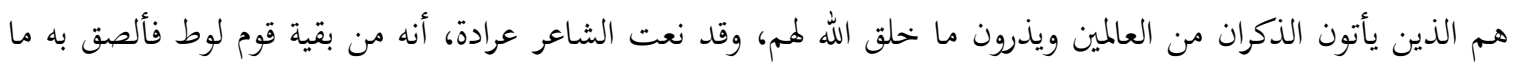

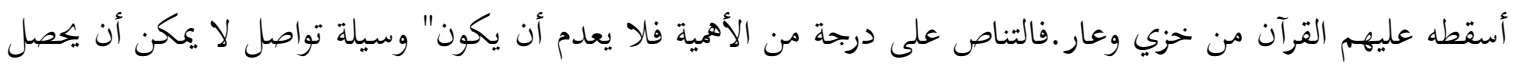
القصد من أي خطاب لغوي بدونه (Miftah 1986).

إنّ "وظيفة التناص الأساسية تكمن في الوظيفة التي يقوم بها، ليخدم هدفا ويقوم بمهمة سياقية ليثري من خلالها

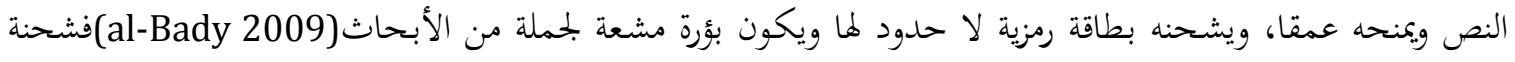

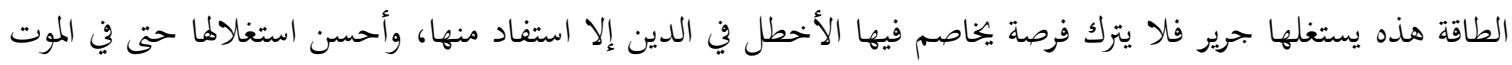

والجنائز كقوله (Tammas 2008):

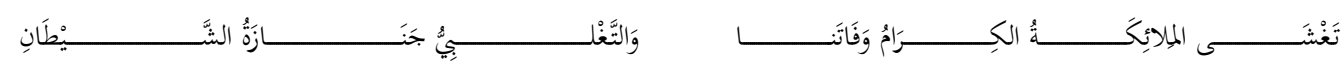

https://doi.org/10.24035/ijit.2.2012.009 
فيستغل الشاعر مخزونه الثقافي الديني الذي جعل منه عصاً غليظة يطرق بها الأخطل فينتقص منه حتى في سبيل الموت، وهو

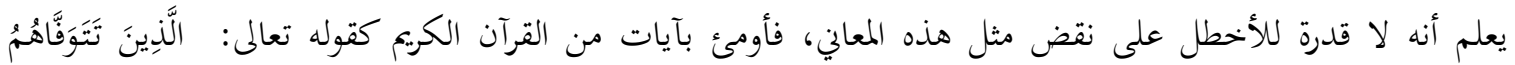

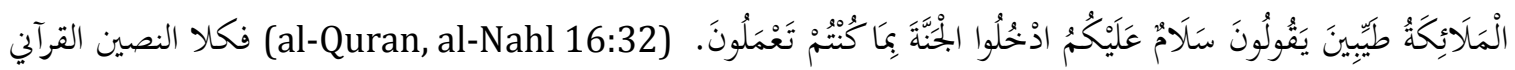
والشعري يعبر عن احتفاء الملائكة بأموات المؤمنين، ولعله استمد عبارة "والتغلبي جنازة الشيطان" من قوله تعالى: فَكَيْفَ إِذَا

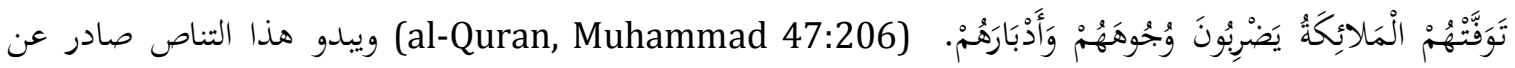
وعي، وهو الذي "يقصد إليه الشاعر أو الكاتب قصدا، ويعرف مصدره ويستخدمه استخداما فنيا له غايته ووظيفته"-al).

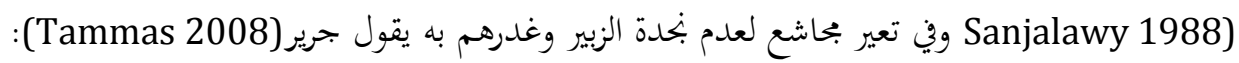

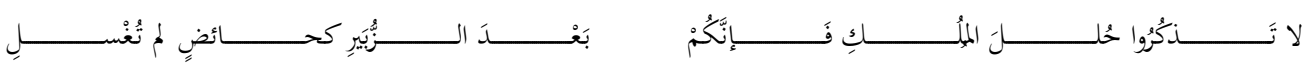

فجعل القذارة والنجاسة التي تلازم بحاشع؛ لغدرهم بالزبير كحال الحائض تنتفي عنها النجاسة بانقطاع الدم والاغتسال، وهو

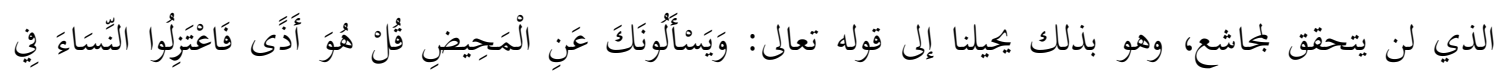

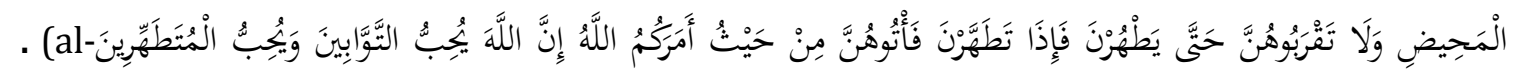
(222: Quran, al-Baqarah 2 وقد امتلك الشاعر مهارة فنية في الإفادة من النص القرآني وأحسن توظيفه والإحالة إليه، ويكشف فضاءات ثقافيه واسعة بتعل القارئ ينتقل إلى لوحات متنوعة بين الشعر والقرآن الكريم. وهذا يعني أن التناص

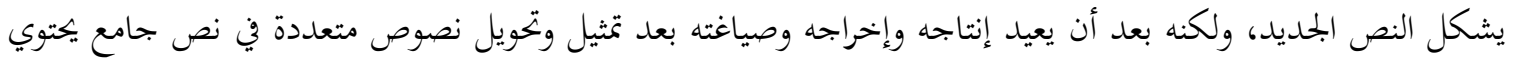
زيادة في المعنى (al-Ruba'iy 2006) . ويستند الأخطل على مثل هذه الإحالات في المدح للخلفاء والولاة، وفي الهجاء كما فعل في هجاء قيس عيلان فيقول (al-Hawy, n.d).

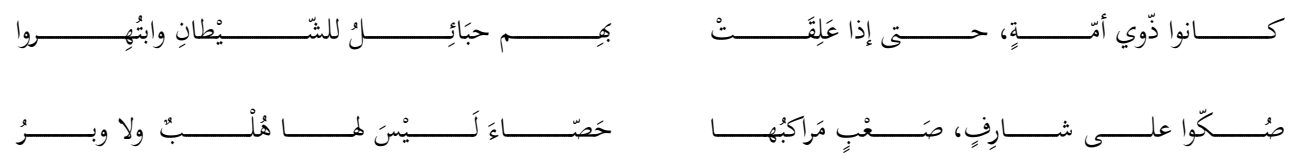

فهم بخروجهم على بني أمية بعد أمنهم ورغد عيشهم كمن يوسوس له الشيطان ويغرر به فيركب مركباً وعراً، يشبه

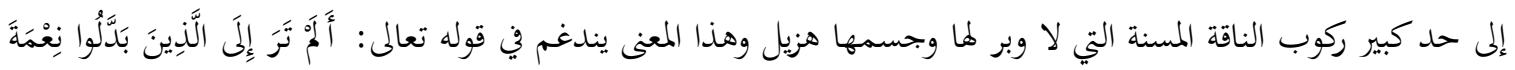

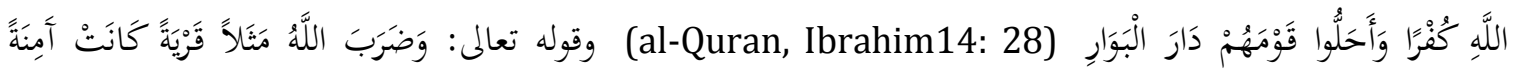

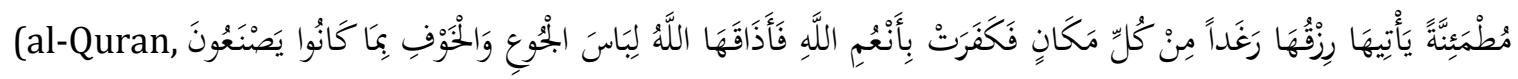
(al-Nahl 16:112) فالشاعر يستمد "جانبا من فكرة النص القرآني ليحذف ، ويضيف بما يتلاءم مع وضعيته النفسية، فالنص القرآين يتكيّف مع النص المنتج" (Abu Sharar 2007) ففي مدح بني أمية يسلك هذا المسلك الذي يرضي

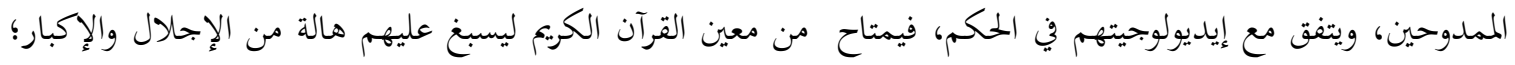

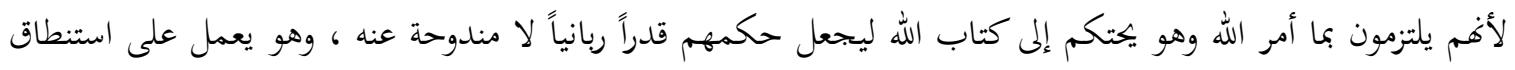




$$
\text { التناص القرآني في شعر النقائض الأموية }
$$

لغة القرآن لتحقيق مراده، فالقرآن الكريم " بجسيد للغّة وللفكر في هذه اللغة، فهو أثر لغوي يبسط على سائر البمالات اللغوية، وفي حضوره المهيمن مغزى خاص، والشعر أحد تلك البحالات المتأثرة باللغة القرآنية" (Abu Sharar 2007) :

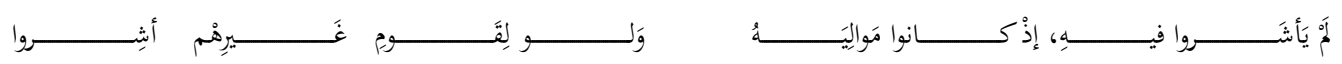

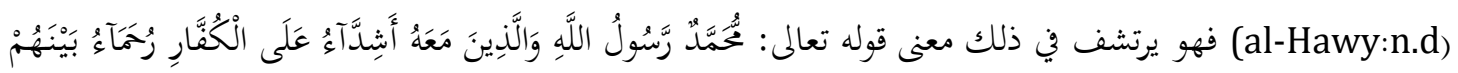

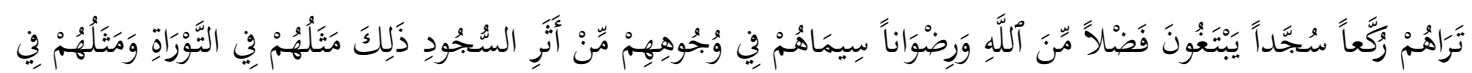

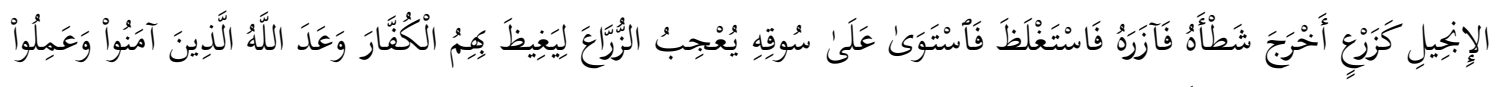

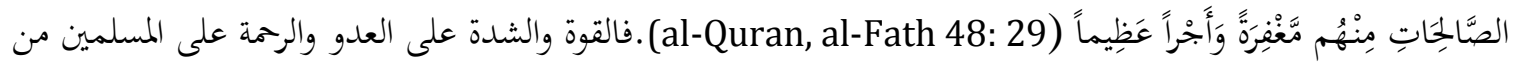
خير ما ينماز به المؤمن.

"ومن هنا استقرت فكرة الارتداد إلى الماضي، وتعامل الشعراء مع التراث، فكل كاتب لا بد له قبل الرجوع، واعيا أو غافلا، إلى كل ما هو ماض والتعامل معه، ولكنه يستخدمه بشكل يحفظ له خصوصيته فيأحذ منه ما يتناسب

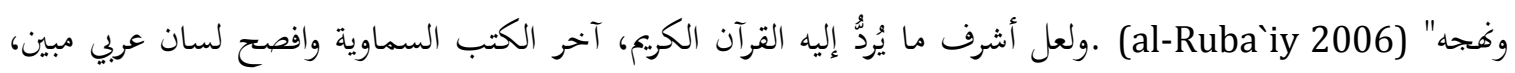
لذالك نتبن مدى تماهي الثقافة القرآنيةبالمنجز الشعري ، حيث استمد الشعراء من نبعه الثر ما يزين قولهم ويقوي منطقهم.

\section{References}

Al-Quran Al-Karim.

Abu Sharar, Ibtisam Musa Abd al-Karim. 2007. al-Tanas al-Qurani wa al-Tarikhi fi Syi 'r Mahmud Darwish. Risalat al-Majistir. Jami'at al-Khalil.

al-Bady, Hussah. 2009. al-Tanas fi al-Shi'r al-Arabi al-Hadith-al-Barghuthy Namudhajan. Amman: Dar Kunuz al-Ma'rifah.

al-Basry, Abu 'Ubaydah Muammar Ibn al-Muthana al-Taymi. 2007. Kitab al-Naqa'id -Naqa'id Jarir wa al-Farazdaq. Beirut: Dar al-Kutub al-'Ilmiyyah.

al-Biqa'i, Muhammad Khir. 1998. Dirasat fi al-Nas w al-Tanasiyyah. Halab: Markaz al-Inma' al-Hadari.

al-Dahun, Ibrahim Mustafa Muhammad. 2001. Al-Tanas fi Shi'r Abi al-'Alaa al-Ma'ri. Irbid: 'Alam al-Kutub.

Fa'ur, Ali. n.d. Diwan al-Farazdaq. Beirut: Dar al-Kutub al-'Ilmiyah.

al-Hawy, Ilya S alim . d.t. Sharh Diwan al-Akhtal al-Taghlabi. Beirut: Dar al-Thaqafah

Ibn Khalifah, Mashry. 2006. al-Shi'riyyah al-Arabiah-Marj'iyyatuha wa Ibdalatuha alNasiyyah. Amman: Dar al-Hamed li al-Nashr wa al-Tawzi'.

al-Kalamy, Najiyah Muhammad. 2008. al-Tanas al-Qurani fi al-Shi'r al-Liby al-Hadith. Majallah al-Satel. Jami'ah al-Sabi' Min October. Libya. al-'Adad. 4.

Miftah, Muhammad. 1986. Tahlil al-Khitab al-Shi'ry Istratijiyah al-Tanas. al-Maghrib: alMarkaz al-Thaqafi al-Arabi.

Muhammad, Abd al-Mutalib. 1995. Qadaya al-Hadathah 'ind Abd al-Qadir al-Jalajani. Cairo: Sharikah Abu al-Haul li al-Nashr.

al-Ruba'iy, Ruba Abd al-Qadir. 2006. al-Balaghah al-Arabiyah wa Qadaya al-Naqd al-Mu'asir. Amman: Dar Jarir. 
al-Sa'dany, Mustafa. 1991. al-Tanas al-Shi'ry Qira'ah ukhra li Qadiyat al-Sariqat. Alexandria: Munsha'at al-Ma'arif.

Shabanah, Naser Jabber. 2007. al-Tanas al-Qurani fi al-Shi'r al-Arabi al-Hadith. Majallah Jami'at al-Najah al-Wataniyyah li al-Abhath (al-'Ulum al-Insaniyah). al-Mujallad 21(4).

Sharrad, Shaltagh Abud. 1987. Athar al-Quran fi al-Shi'r al-'Arabi al-Hadith. Damascus: Dar al-Ma'rifah.

al-Sinjalawy, Ibrahim. 1988. Dalalat al-Tadmin fi Khawatim Qasaid Abi Nawas. Damascus: Majallah Jami'at Dimashq. al-'Adad (9).

Tammas, Hamdu. 2008. Diwan Jarir. Beirut. Dar al-Ma'rifah.

al-Yasu'iy, Antwan Salihani. 1922. Naqa'ad Jarir wa al-Akhtal. Beirut: al-Matba'ah alKathulikiyah li al-Aba' al-Yasu'iyyen. 